\title{
Audience reach of science on television in 10 European countries: An analysis of people-meter data
}

Public Understanding of Science 2016, Vol. 25(2) 223-235

(C) The Author(s) 2014

Reprints and permissions: sagepub.co.uk/journalsPermissions.nav DOI: 10.1 I77/09636625।4536295 pus.sagepub.com

\section{Markus Lehmkuhl}

Free University of Berlin, Germany

\section{Pepka Boyadjieva}

Bulgarian Academy of Sciences, Bulgaria

\section{Yvonne Cunningham}

Dublin City University, Ireland

\section{Christina Karamanidou}

University of Peloponnese, Greece

\section{Tuomo Mörä}

University of Helsinki, Finland

\section{AVSA-Team*}

\begin{abstract}
Beginning with a differentiation of science programmes into five different editorial concepts, this article explores the audience reach of science on television in 10 European countries with a special emphasis on young audiences aged between 14 and 29 years. In relation to the share of this age group in the entire population, science programmes in all countries reach a considerably smaller proportion of younger viewers. Specific preferences for science content on television do not seem to be relevant in explaining aggregated viewing behaviours especially of young audiences. Unlike all other segments, the young science viewer segment is almost intangible as an aggregated group, as a definable segment of a mass audience that can be targeted by science programme makers.
\end{abstract}

\section{Keywords}

people-meter data, science audiences, science in TV, youth and science

*Lucie Schiebel, Esa Väliverronen, Kostas Dimopoulos, Vasilis Koulaidis, Kristina Petkova, Brian Trench

Corresponding author:

Markus Lehmkuhl, Institute for Media and Communication Studies, Free University of Berlin, Garystraße 55,

Berlin 14195, Germany.

Email: kuhle@zedat.fu-berlin.de 


\section{Introduction}

This study originates in a former study, in which we have identified and typified all TV science programmes in several European countries that have been broadcast between 2007 and 2008. In that study, we identified three factors that influence volume and structure of programme offers, namely, the fragmentation of national TV markets, the presence of middle-sized commercial channels and the weight of market forces on public service broadcasters (Lehmkuhl et al., 2012). These factors contribute to an answer of why TV treats science the way it does. But it goes without saying that other factors must be investigated in addition.

The explanation of the presence or absence of science programmes must also include the popularity of these programmes in European societies. This is especially relevant for the TV market that is driven by various audience measuring tools, the most important of which are daily television ratings derived from people-meters (Eastman and Ferguson, 2012; Koch-Gombert, 2010; Webster et al., 2005).

These measuring tools enable a basic interplay that Webster (2011) termed the 'duality of media'. While people are free to tune into a science programme or any other programme on television, they can only choose from a limited body of programmes on offer, a structure of supply that, through their actions, they help reproduce and alter (Webster, 2009).

This basic interplay between supply and demand has received little attention from media scholars who are still heavily biased in favour of psychological causes for television exposure (Webster, 2009). Even though there are models of various influences on media exposure apart from psychological causes which also include the given media system's offerings (McQuail, 2010: 422; Schweiger, 2007; Webster and Wakshlag, 1983), we are not aware of any studies that aim at describing viewers' exposure to science TV programmes from the perspective of content producers. Accordingly, media studies treat production and use of clearly defined television content as separate spheres. This applies to both perspectives, one of which is commonly referred to as viewer activity and the other as viewer passivity (Livingstone, 2003).

The first perspective focuses on individual determinants to explain why audiences choose certain media, channels or programmes. This perspective is known as the 'uses and gratifications' approach. From this perspective, programme choice results from the gratifications that a user seeks and obtains through different programme types or specific programmes. Tuning into a medium, channel or programme is described as active, rational behaviour that aims to obtain distinctive gratifications (for example, Dehm, 2008).

The second perspective emphasises characteristics such as scheduling factors or audience availability that influence the size and composition of television audiences relatively independently of preferred content or gratification sought. From this perspective, television users are mostly portrayed as passive recipients of what media professionals offer them (e.g. Zubayr, 1999).

Compared to the research branches mentioned, the perspective of this study is totally different. It does not use quantitative data to learn more about expectations or motives of science audiences (Dehm, 2008) or about the flow of audiences (Zubayr, 1999). We propose to treat aggregated audience data as the most relevant currency for producers of TV content. Of special relevance are young audiences.

Particularly, commercial channels view their audiences primarily as merchandise to be offered to the advertising markets. Young people are of particular interest here, since their consumer behaviour and needs are considered more manipulable than those of older people. Particularly for public television, young audiences play a significant role in assuring the channels' very legitimacy: almost Europe-wide, public television is bound by the double normative mission of appropriately integrating science and education into its programme portfolio, and reaching all age groups in society in order to act as an integrating force (Open Society Institute, 2005, 2008). 
Young people are the focus since they are considered to be agents of social change, particularly if their orientation and behaviour continue to colour patterns in later life through the so-called cohort effect (Best and Engel, 2011; Rosengren et al., 1994): 'Youth is what is young and what belongs to the future' (Drotner, 2000: 150).

\section{Theoretical framework}

An attempt to unlock the 'duality of media' requires a theoretical clarification of the 'media structure' that interplays with aggregated actions of media users. In our context, the term refers to a pattern of science programmes offered by various television channels. To profile this pattern and to link it with specific, content-related media use, we need a definition of science programmes that integrates the agency of media professionals and media users. A term commonly used in media studies is programme genre. Programme genres help media users find their way through various programmes and facilitate media production by helping to establish routines to satisfy audience expectations (Hallenberger, 2002).

Unfortunately, the term 'genre' is only of limited value for defining the programme category 'science programme' (Bonner, 2003). Since science finds its way into various programme genres, the term seems inadequate for concluding a contract between media professionals and their audiences. Magazine programmes, documentaries, even quizzes or reality shows are used to raise awareness of science on television. Hence the term 'science programme' is neither suited to describing specific expectations of audiences nor to facilitating television professionals' selection and reconstruction of science content.

The main theoretical challenge thus lies not primarily in the definition of what a science programme actually is. This can be done by a nominal definition. In this context, a science programme is defined as

1. a programme that reports on research findings or events related to the natural and social sciences, humanities or to applied sciences such as engineering and medicine (Bauer et al., 2006; Bucchi and Mazzolini, 2003) and/or

2. a programme that links scientific expertise or scientific findings related to the natural and social sciences, humanities or applied sciences such as engineering and medicine with social, political, economic or everyday topics (Hijmans et al., 2003).

A programme is considered a science programme if it mainly or exclusively covers science content in one of the ways stated. ${ }^{1}$

The main theoretical challenge is to achieve a meaningful breakdown of the heterogeneous body of programmes covered under this nominal definition by the routines they use to establish and protect the bond with their audiences. In this context, we need to turn to theories on how journalism protects its bond with audiences in general and with science audiences in particular, and the different ways in which organisational units like science programmes are trying to gain attention for their products.

Basically, statements gain attention based on their informational value. A statement is informative if it is 'new', that is, if it was previously unknown to recipients, and if it is relevant to the recipient (Luhmann, 2005; Merten, 1973; Ott, 2004). Informational value is a contingent category. What is new and relevant for one individual might already be known and irrelevant to another. Hence, there are an infinite number of messages which could potentially gain attention.

In order to produce regular messages that can gain attention, journalism sections such as science programme departments must follow selection routines. Studies influenced by systems theory have used the term 'decision-making programmes' (Rühl, 2002); these enable journalism to reconstruct 
the world by reducing hyper-complexity. These routines serve to protect the bond between journalism and its audiences (Rühl, 2002: 318). Lublinski (2004, 2008, 2011), who studied three German radio science programmes and a news agency extensively through participant observation, summarised these decision-making programmes under the term 'editorial concepts'.

Lublinski identified key decisions within specialist science units which influenced how media professionals working for these programmes reconstructed science. These decisions affect which topic areas are monitored continuously, the exact application of the news value of timeliness and the 'special processes of how to select and reconstruct an issue' (Lublinski, 2004: 95).

Based on these considerations, we have empirically identified five different editorial concepts which represent science programme producers' different ways of protecting their bond with audiences. This has been done by a content analysis which is described in detail elsewhere (Lehmkuhl, 2012, 2013; Lehmkuhl et al., 2012).

1. Information programmes try to protect their bond with audiences by providing science news that is or can become socially relevant. Their purpose is to keep audiences up to date with recent developments from within various science disciplines. Examples are the German programmes nano, Odysso or neues, and the Swedish programme Vetenskapsmagasin.

2. Popularisation programmes (mostly documentaries) are, like Information programmes, oriented primarily towards deriving information from science. Unlike Information programmes, they place scientific findings into a wider context and aim to provide background information. This implies a longer audience attention span than is the case for Information programmes, which consist of several short items rather than one single item about a specific science topic. The main challenge does not lie in the selection of relevant scientific news and a quick reconstruction, but in developing communication techniques which engage the media user with a topic relatively intensely. Examples are Newton (Austria), Terra X (Germany) or Horizon (United Kingdom) which are probably the best known popularisation programmes that are imported frequently especially by Scandinavian public service channels.

3. Edutainment programmes are guided by the aim to educate and entertain audiences using scientific ideas and processes. They typically try to enrich people's experience by providing unfamiliar or surprising scientific explanations of things that are, in a broad sense, part of their everyday lives. This type of programme often answers questions such as why the sun goes down, why one gets wet more quickly in the rain when running, what happens if one places a broomstick into a specially prepared blender or sticks one's head into a bubble of helium. The selection of topics, unlike in Information and Popularisation programmes, is not guided by the observation of developments within the science system. These programmes want to deliver surprising connections between everyday phenomena and scientific explanations and present these explanations in an accessible form. Examples are Kopfball (Germany), Forscherexpress (Austria), Rough Science (United Kingdom and imported by Finland) and C'est pas sorcier (France).

4. Health Advice programmes are characterised by their topics, have short preparation times and give advice on, for example, healthier living. The selection of topics and processing of the selections are primarily guided by the necessity to provide recipients with clear and unambiguous tips. The selection of topics is more likely to come from the viewers' own realm of experience. Examples are Saber vivir (Spain) or Sanatate pentru toti! (Bulgaria).

5. Advocacy programmes or Environmental programmes focus on fulfilling a specified need, the social need of environmental protection. Although these programmes occasionally report on recent science studies, their primary feature is to link scientific expertise with 
political topics such as new water supply regulations, saving energy or 'natural' topics such as disasters. Examples are Osoon (Estonia), Mera natur (Sweden), Umwelt (Germany) or El medi ambient (Spain).

Similarly to programme genres, these concepts represent each a contract between media producers and their audiences. They can feed specific expectations regarding content as well as content selection and content reconstruction by media professionals. In this context, these concepts and their distribution among channels are thus our specification of the 'media structure' that can interplay with aggregated audience behaviour.

\section{Research questions}

After having clarified how exactly we intend to unlock the duality of media, we can now use these concepts to specify our research questions. We want to explore,

RQ1: whether one of the editorial concepts gets higher ratings by European audiences at large;

RQ2: whether one of the editorial concepts gets higher shares of economically relevant audiences, of special relevance are young audiences aged between 14 and 29 years;

RQ3: whether editorial concepts contribute to an explanation of differently shaped audiences.

The answers will then be used to discuss the probability whether aggregated audience behaviour can influence the structure of science programme offers on a European level, that is, a macro level.

\section{Method}

As mentioned in the introduction, this study originates in a former study which has identified and classified 439 TV programmes in several European countries into the five different editorial concepts introduced above. To respond to our research questions, it is not adequate just to compare the ratings of all these programmes. This is due to the fact that the different editorial concepts are not evenly distributed among central categories that influence the ratings independent from content, namely, among the time when scheduled (peak time/off peak time), among channels and among national markets which differ regarding their degree of fragmentation. This is why we created an artificial sample that controls for these influences. In the following paragraphs, we will briefly describe and justify the creation of the sample.

The scheduling time is relevant since it refers to hourly variations of the size of the potential audience. It goes without saying that an investigation of different programme-type ratings does not produce meaningful results, if one type is predominantly scheduled outside prime time, while the other mainly at peak time. This is why we created a sample in which the share of programmes scheduled at prime time is nearly equal among the five different editorial concepts.

The size of the channels is relevant since it influences inter alia the viewer awareness of the programmes provided. Programmes broadcast on small channels have not the same chance to reach big audiences as programmes on big channels independent from content (Eastman and Ferguson, 2012; Webster et al., 2005). This is why we created a sample in which the share of programmes broadcast on big channels $(>10 \%$ market share) is nearly equal among the different editorial concepts. 
Table I. Distribution of the sample across programme-type categories in percent $(N=210)$.

\begin{tabular}{llllll}
\hline & $\begin{array}{l}\text { Information } \\
(n=10)\end{array}$ & $\begin{array}{l}\text { Popularisation } \\
(n=115)\end{array}$ & $\begin{array}{l}\text { Edutainment } \\
(n=43)\end{array}$ & $\begin{array}{l}\text { Advice } \\
(n=24)\end{array}$ & $\begin{array}{l}\text { Advocacy } \\
(n=18)\end{array}$ \\
\hline Peak time & 40 & 43 & 44 & 50 & 39 \\
Big channels & 40 & 35 & 40 & 34 & 38 \\
Highly fragmented markets & 50 & 49 & 48 & 46 & 44 \\
Fragmented markets & 30 & 29 & 33 & 33 & 28 \\
Poorly fragmented markets & 20 & 22 & 19 & 21 & 28 \\
\hline
\end{tabular}

Peak time lasts from 7:00 to I I:00 p.m.; big channels have more than 10\% market share: highly fragmented markets (Germany, Greece), fragmented markets (Spain, Sweden, Austria, Ireland) and poorly fragmented markets (Bulgaria, France, Finland, Estonia).

The fragmentation of a market is relevant since in highly fragmented markets with many channel options like in Germany, Spain or Greece, a programme has not the same chance to reach big audiences as in poorly fragmented markets like in France, Finland, Bulgaria or Estonia (Ceteris paribus) (Eastman and Ferguson, 2012; Peters et al., 2012). This is why we created a sample in which the share of programmes broadcast in highly fragmented (Germany, Spain, Greece), fragmented (Sweden, Austria, Ireland) and poorly fragmented markets (Estonia, France, Finland, Bulgaria) is nearly equal. To distinguish the national markets, we used accumulated market shares of the two biggest and the four biggest channels (Lange, 2009):

- If the accumulated market share of the two biggest channels is lower than $40 \%$ and if the accumulated market share of the four biggest channels is lower than $66 \%$, we classified a market as highly fragmented.

- If the accumulated market share of the two biggest channels is higher than $40 \%$ and if the accumulated market share of the four biggest channels is lower than $66 \%$, we classified a market as fragmented.

- If the accumulated market share of the two biggest channels is higher than $40 \%$ and if the accumulated market share of the four biggest channels is higher than $66 \%$, we classified a market as poorly fragmented.

The sample created contains 210 programmes; this represents approximately $60 \%$ of all identified programmes in the 10 selected European countries. This sample is balanced in accordance with the factors mentioned above.

Table 1 reports the distribution of the sample across crucial factors that influence audience rates independent from content. As the table indicates, all editorial concepts are roughly evenly distributed. This enables a comparative analysis of ratings with regard to our research questions.

The sample is not evenly distributed across countries. Hence, valid cross-country comparisons of audience rates and shares of audiences are beyond the scope of this study.

We received audience data for the selected programmes from specialised agencies (Nielsen Media Research, GfK, Médiamétrie, etc.). The unit of analysis is the average rate of audience exposure (14+) to a certain programme within a time span of 12 months between 2007 and 2008 . For example, we calculated the mean of the exposure rates of all editions of a weekly programme within a time span of 12 months. 


\section{Findings}

By using the sample, which controls important factors that influence audience rates independent from content, we first compared the average rates each editorial concept reached (Table 2)

Table 2. Average viewing rates by programme types in 10 European countries. ${ }^{\mathrm{a}}$

\begin{tabular}{lllc}
\hline Editorial concept & Average viewing rate in \% & Standard deviation & Number of programmes \\
\hline Information & 1.9 & 2.1 & 10 \\
Popularisation & 1.2 & 1.5 & 115 \\
Edutainment & 1.3 & 1.6 & 43 \\
Advice & 1.9 & 2.7 & 24 \\
Advocacy & 1.0 & 1.4 & 18 \\
F-value (3.56) & 1.2 (n.s.) & & $\Sigma=210$ \\
\hline
\end{tabular}

${ }^{a}$ Austria, Bulgaria, Estonia, Finland, France, Germany, Greece, Ireland, Spain and Sweden.

On average, each programme in our sample reached $1.31 \%$ of the overall population in 10 European countries. This accounts for about 300,000 viewers per programme. The differences between the programme types are slim, with a low $F$-value of 1.2. This means with regard to our first research question, there is no evidence that the size of aggregated audiences is related to the editorial concept.

To respond to our second research question we report first on the share of three different age groups watching science programmes in 10 European countries. As Table 3 shows, the share of young audiences is dramatically lower than the share of young people in the population as a whole. Far less drastically, but also still considerably lower, is the share of audiences aged between 30 and 49 years. The audience for science programmes is thus fairly old.

Table 3. Comparison of audience shares reached by science programmes in Europe with their share of the population $(N=210)$.

\begin{tabular}{lllcc}
\hline Age group (years) & Average share in \% & Share of population in \% & Difference & $t$-value \\
\hline $14-29$ & 11 & 24 & -13 & $-15.95 * *$ \\
$30-49$ & 28 & 33 & -5 & $-3.79 *$ \\
50 plus & 61 & 43 & 17 & $11.09 * *$ \\
\hline
\end{tabular}

$* * p<.001 ; * p<.05$.

Although we cannot make cross-country comparisons with this particular sample of programmes, it is notable that we have not identified a single country in Europe where the audience share of young people came close to their share of the overall population. The share of young science audiences is between 7 basis points (France) and 15 basis points (Greece) lower. Even the share of people aged between 30 and 49 years is mostly considerably lower than their share of the overall population ( -12 and -7 basis points). Only in Austria and in Ireland did middle-aged science audiences approximate their share of the overall population.

Second, we will explore whether these low shares affect all editorial concepts in the same way or whether there are significant differences (Table 4). 
Table 4. Average share of young viewers (14-29 years) by programme types.

\begin{tabular}{lccc}
\hline Editorial concept & $\begin{array}{l}\text { Share of viewers 14-29 } \\
\text { years in \% }\end{array}$ & Standard deviation & Number of programmes \\
\hline Information & 9.6 & 6.2 & 10 \\
Popularisation & 11.1 & 10.4 & 115 \\
Edutainment & 15.8 & 11.1 & 43 \\
Advice & 8.5 & 7.6 & 24 \\
Advocacy & 10.9 & 8.8 & 18 \\
F-value & 2.25 (n.s.) & & $\Sigma=210$ \\
\hline
\end{tabular}

Means do not differ significantly $(p<.05)$ according to Duncan's post hoc test for multiple comparisons.

Although, on average, Edutainment programmes reached almost twice as high shares of young audiences as Health Advice programmes, the differences are not significant. This is certainly due to the low numbers of sample items in some of the categories. When we match the categories Information and Advice, the difference between Edutainment programmes and the newly created category becomes significant $(p<.05)$. However, given our findings, there is no convincing evidence that the low shares of young science audiences are related to any specific editorial concept. Instead, the programme category 'science programme' as a whole did not appear to be very attractive to young audiences. Every single concept reached a considerably lower share of young people when compared to their share of the overall population. Only Edutainment programmes obviously have the potential to attract slightly more young people than other science programme types.

More apparent are differences in the group aged between 30 and 49 years. Edutainment programmes reached the highest shares of middle-aged science audiences (35\%), followed by Advocacy programmes (32\%). Health Advice programmes reached the smallest share of middleaged audiences (20\%). Popularisation programmes $(28 \%)$ reached significantly lower shares of middle-aged audiences than Edutainment programmes, and significantly higher shares than Advice programmes.

In the viewer group aged over 50 years, we also found significant differences between Edutainment, Advice and Popularisation programmes, although the differences are transverse. Edutainment programmes reached significantly lower shares than all other editorial concepts; Health Advice programmes reached significantly higher shares compared with all other concepts except Information programmes. Popularisation programmes reached lower shares than Advice programmes, but higher shares than Edutainment programmes.

With regard to RQ2, we can state that we cannot find any evidence for preferences especially of young audiences that can be related to an editorial concept. Concept-related differences of the programmes are obviously less relevant to young audiences than they are to older people. From the point of view of producers, preferences of the middle-aged segment are of particular relevance. This group shows a preference for Edutainment programmes and for Advocacy programmes. And it shows a certain aversion against Advice Health programmes, an editorial concept that is particularly favoured by audiences older than 50 years.

To respond to our last RQ (RQ3), we put different audience compositions into the wider context of other relevant factors that influence programme choice behaviour on an aggregated level (Webster and Wakshlag, 1983). We calculated three regression models, using audience shares of the three age groups as the dependent variable, scheduling, channel characteristics and selected editorial concepts as independent variables (Table 5).

The models explained between $16 \%$ and $33 \%$ of the variance dependent upon the age group considered. As the detailed analysis has already suggested, in contrast with older audiences, the 
Table 5. Gradual multiple regression by age groups $(N=210)$.

\begin{tabular}{llll}
\hline Predictors & $14-29$ & $30-49$ & $50+$ \\
\hline Scheduling & & & \\
Weekdays/weekend & Excluded & $.12^{*}$ & Excluded \\
Off peak/peak hours & $-.12^{+}$ & Excluded & $.17^{* *}$ \\
$\quad$ Not regular/regular & Excluded & $.25^{* *}$ & $-.18^{*}$ \\
$\begin{array}{l}\text { Channel } \\
\quad \text { Public/Private }\end{array}$ & $.33^{* *}$ & $.20^{*}$ & $-.34^{* *}$ \\
$\quad$ Market share & $.17^{* *}$ & Excluded & Excluded \\
Editorial concept & & & \\
$\quad$ Edutainment & Excluded & $.13^{*}$ & $-.20^{* *}$ \\
$\quad$ Popularisation & Excluded & Excluded & Excluded \\
$\quad$ Advice & Excluded & $-.25^{* *}$ & $.23^{* *}$ \\
$R^{2}$ & $.16^{* *}$ & $.24^{* *}$ & $.33^{* *}$ \\
\hline
\end{tabular}

${ }^{+} p<.10 ; *_{p}<.05 ; * * p<.001$.

editorial concepts of media producers do not serve well to explain the average shares of young audiences that science programmes reach in Europe. Instead, channel characteristics are the key factor when explaining differences in young science audience ratios. The probability of reaching a comparatively higher share of young audiences increases especially if science programmes are provided by commercial channels. Scheduling is also of certain relevance. The probability of reaching a comparatively higher share of young science audiences increases if science programmes are scheduled outside peak hours.

We thus cannot identify content-related factors that may increase the probability of reaching a higher share of young audiences. On this level of analysis, the share can only be linked to factors unrelated to content.

Whether or not a channel is commercial does also contribute significantly to an explanation of the shares of older audiences. This points to a development in multi-channel situations, which we find almost everywhere in Europe today: The notion of 'programme' is losing importance to the notion of 'channel' in the sense that programme contents which would be appealing to certain age groups do not reach them, merely because the programmes are not broadcast within the age group's favoured canon of channels. Detailed analyses from Germany impressively show that the variety of channels leads to a segmentation of the viewership (Peters et al., 2012).

The audiences produce patterns of channel use with no overlap. Group A watches different channels from group B, and group B watches different ones from group C. It limits the integrating power of the television medium when certain content is very unevenly distributed across channels, so that certain viewer groups do not even come into contact with certain content due to their different channel preferences.

This is precisely the case with science programmes. Science programmes are mainly offered by public television channels in all the countries studied. The number of public channels correlates highly significantly with the number of science programmes offered (Spearman's rho $=.85 / \mathrm{p}<.001$ ). Private channels do not substantially contribute to the choice of science programmes, which is not surprising given the lack of appeal of these programmes among the commercially highly essential viewer segment. Because younger viewers, in particular, favour commercial channels, yet the latter do not contribute much to the choice, there is a significant negative correlation between the number of commercial channels and the proportion of young viewers that science programmes will reach (Spearman's rho $=-.67 / \mathrm{p}<05$ ). As a consequence, via age-specific channel preferences, the 
market-driven growth of national commercial channels limits opportunities for science programmes to reach young people.

\section{Discussion}

This study was the first to analyse science TV audiences in detail, with a special focus on young people. The results tend to encourage pessimistic attitudes about whether science contents on European television can even reach young people. It also shows that for specialised science programmes, the issue of reach is not limited to very young audience segments. The segment of 30- to 49-year-olds must also be considered here, since the reach of science programmes within this group does not correspond with its share of the overall population.

Before concluding on a specific lack of interest in science programmes among young people, we need to check whether different proportions reflect differences in overall television consumption among the various age groups. Even though there are no detailed data available for all countries, one can assume that older viewers spend more time in front of a television than younger ones. In Germany in 2010, for example, older viewers spent about 30\% more time watching television (290 minutes) than the average. Younger viewers aged between 14 and 29 years watched 39\% less television (135 minutes) than the average (223 minutes). Media use among viewers aged 30-49 years was insignificantly lower than average (Zubayr et al., 2011). In order to compensate for the significant variations in audience structure for science programmes, however, the younger European viewer segments would only have to watch half as much television as the average. The older segments would have to watch more than twice as much as the average. We can therefore assume that the difference between younger and older viewers measured against their share of the overall population is somewhat levelled by the differences in media use; yet they still can be interpreted as evidence that this type of programme indeed does not reach both young and middle-aged audiences as much as one would expect based on their share of the overall population.

Although the group of middle-aged viewers proves difficult, unlike the younger viewers, their share can be partly explained by their preferences for certain programmes types - that means their share correlates with preferences for and aversions to certain editorial concepts, in particular with regard to Edutainment and Health Advice programmes. This age group, which is vital to television stations commercially, can thus still be targeted as an aggregate group by media professionals, which in turn can impact on the structure of the science programme portfolio.

The programme category of 'science programme' as defined here, however, is itself problematic when it comes to young viewers between the ages of 14 and 29 years. None of the editorial concepts has the potential to reach a large section of young viewers, with the minor exception of Edutainment programmes, which reach a higher share of young viewers. This difference is so minor, however, that it does not cross the significance threshold. This shows that in this segment, this age group does not choose programmes based on any clearly defined expectations towards the medium of television for scientific information.

In this, we see two possible explanations that may not be unrelated to one another: One reason might be that the age group of 14- to 29-year-olds is so heterogeneous and its media use so individualised that they are hardly tangible as one group. Second, young people might in principle share programme-type preferences, but in such a way that they cannot be grasped by a general classification of editorial concepts.

Each of the concepts distinguished here includes a body of programmes that are to some extent quite heterogeneous and differ from each other in various ways within the categories we selected for this study. This is particularly true for Edutainment, which enjoys the highest share of young viewers. 
There are many different ways to link concrete scientific explanations to real-life experiences in the broadest sense. The English programme 'Rough Science', for example, sent scientists to a deserted island without any aids for several days and had them solve various everyday problems there. Other Edutainment formats also relied on a manipulation of the everyday world in order to stir interest. Still others focused on the scientific, limiting themselves to an explanation of factual everyday phenomena such as why we sleep and so on. Edutainment programmes can thus be further differentiated by whether they use an interesting scientific explanation to connect with the audience's interest, or whether they seek to maximise the interest value by manipulating everyday life and relegating the scientific explanation to the sidelines - which raises the question as to whether they ought to be counted among science programmes at all.

We find indicators that it is mainly the latter type of the so-called Edutainment programmes that reach the highest numbers of young viewers. The very successful programmes in this group with a share of young viewers of more than $14 \%$ contain a significantly higher proportion of segments in which the link to science becomes very indistinct. We thus see indicators that young people slightly favour the category of Edutainment over others because this type of programme, in particular, contains a relatively large number of programmes where science is not of central importance for gaining attention.

Which of the explanations is more applicable needs to be left to studies using a different methodological approach. However, the consequence is the same: To those in charge of making programmes, the young viewer segment is almost intangible as an aggregate group, as a definable segment of a mass audience with differentiable preferences regarding science content. This is the decisive difference between this and the other two age groups analysed in this study. Due to the lack of appeal of all editorial concepts, we found very little evidence that the popularity of TV science programmes can stimulate the volume and/or the structure of supply in Europe positively.

\section{Acknowledgements}

The authors thank the anonymous reviewers for their detailed reading of an earlier version of this article.

\section{Funding}

The author(s) disclosed receipt of the following financial support for the research, authorship, and/or publication of this article: This study was undertaken as part of the Audio-Visual-Science Audiences (AVSA) project, 2008-2010, funded by the European Commission's Seventh Framework Programme.

\section{Note}

1. For further explanation, please download 'Definition of Science Programmes' from our project website http://www.fu-berlin.de/avsa

\section{References}

Bauer MW, Petkova K, Boyadjieva P and Gornev G (2006) Long-term trends in the public representation of science across the 'Iron Curtain': 1946-1995. Social Studies of Science 36(1): 99-131.

Best S and Engel B (2011) Alter und Generation als Einflussfaktoren der Mediennutzung [Age and Generation as factors influencing media use]. Media Perspektiven 2: 525-542.

Bonner F (2003) Ordinary Television: Analyzing Popular TV. London, Thousand Oaks, New Delhi: SAGE. Bucchi M and Mazzolini RG (2003) Big science, little news: Science coverage in the Italian daily press, 1946-1997. Public Understanding of Science 12(1): 7-24.

DehmU (2008)Zwischen Lust und Lernen-Wissens- und Wissenschaftssendungen: Ergebnisse, Möglichkeiten und Grenzen von Medienforschung [Between delight and learning - Science TV Programmes]. In: 
Hettwer H, Lehmkuhl M, Wormer H and Zotta F (eds) WissensWelten. Wissenschaftsjournalismus in Theorie und Praxis. Gütersloh: Verlag Bertelsmann Stiftung, pp. 483-500.

Drotner K (2000) Difference and diversity: Trends in young Danes' media uses. Media, Culture \& Society 22: $149-166$.

Eastman S and Ferguson D (2012) Media Programming: Strategies and Practices, 9th edn. Boston, MA: Cengage Learning.

Hallenberger G (2002) Das Konzept 'Genre': Zur Orientierung von Medienhandeln [The concept of "genre": On orientation of media use]. In: Gendolla P, Ludes P and Roloff V (eds) Bildschirm - Medien Theorien. Munich: Wilhelm Fink Verlag, pp. 83-110.

Hijmans E, Pleijter A and Wester F (2003) Covering scientific research in Dutch newspapers. Science Communication 25(2): 153-176.

Koch-Gombert D (2010) Aufgaben und Strategien der Programmplanung im klassischen Free-TV und im digitalen Wettbewerb [Duties and strategies of programme design in classic free-TV and digital competition]. In: Lantzsch K, Altmeppen K-D and Will A (eds) Handbuch Unterhaltungsproduktion. Wiesbaden: VS Verlag für Sozialwissenschaften, pp. 180-194.

Lange A (2009) Television in 36 European States. Strasbourg: European Audiovisual Observatory.

Lehmkuhl M (2012) Wissenschaft im österreichischen Fernsehen. Zum Zusammenhang von TV-Marktstrukturen und Programmangeboten am Beispiel spezialisierter Formate [Science in Austrian TV. The relationship between TV market structures and supply]. In: Steininger C and Woelke J (eds) Fernsehen in Österreich 2011/2012. Konstanz: UVK, pp. 211-228.

Lehmkuhl M (2013) Wissenschaftsformate im deutschen Fernsehen im internationalen Vergleich. Zum Einfluss der Segmentierung des Marktes auf das Angebot [International comparison of science programme offers in German TV. Segmentation of markets and its influence on supply]. Publizistik. Vierteljahreshefte für Kommunikationsforschung 58(4): 409-426.

Lehmkuhl M, Karamanidou C, Mörä T, Petkova K, Trench B and AVSA-Team (2012) Scheduling science on television: A comparative analysis of the representations of science in 11 European countries. Public Understanding of Science 21(8): 1002-1018.

Livingstone S (2003) The Changing Nature of Audiences: From the Mass Audience to the Interactive Media User. London: LSE Research Online. Available at: http://eprints.lse.ac.uk/archive/00000417

Lublinski J (2004) Wissenschaftsjournalismus im Hörfunk: Redaktionsorganisation und Thematisierungsprozesse. Science Journalism in Radio. Konstanz: UVK-Verlag-Ges.

Lublinski J (2008) dpa und WDR - Redaktionsalltag und Redaktionsforschung [dpa and WDR - Daily routines in science sections]. In: Hettwer H, Lehmkuhl M, Wormer H and Zotta F (eds) WissensWelten: Wissenschaftsjournalismus in Theorie und Praxis. Gütersloh: Verlag Bertelsmann-Stiftung, pp. 279296.

Lublinski J (2011) Structuring the science beat. Journalism Practice 5(3): 303-318.

Luhmann N (2005) Soziologische Aufklärung 3: Soziales System, Gesellschaft, Organisation [Sociological Enlightenment 3: Social System, Society, Organisation]. Wiesbaden: VS Verlag für Sozialwissenschaften.

McQuail D (2010) McQuail's Mass Communication Theory. Los Angeles, London, New Delhi, Singapore, Washington DC: SAGE.

Merten K (1973) Aktualität und Publizität. Zur Kritik der Publizistikwissenschaft [Timeliness and Publicity. Reviewing the "Publizistikwissenschaft"]. Publizistik 3: 216-235.

Open Society Institute (ed.) (2005) Television across Europe: Regulation, Policy and Independence. Budapest: Open Society Institute.

Open Society Institute (ed.) (2008) Television across Europe: More Channels, Less Independence. Budapest: Open Society Institute.

Ott S (2004) Information: Zur Genese und Anwendung eines Begriffs [Information: Genesis and Use of a term]. Konstanz: UVK.

Peters B, Niederauer-Kopf K and Eckert M (2012) Die individualisierte Fernsehnutzung. The individualised TV use Analysen zur Verweildauer und zum Relevant Set. Media Perspektiven 2: 72-77.

Rosengren K-E, Johnsson-Smaragdi U and Sonesson I (1994) For better and for worse: Effects studies and beyond. In: Rosengren K-E (ed.) Media Effects and beyond: Culture, Socialization and Lifestyles. London: Routledge, pp. 133-149. 
Rühl M (2002) Organisatorischer Journalismus. Tendenzen der Redaktionsforschung. In: Neverla I, Grittmann E and Pater M (eds) Grundlagentexte zur Journalistik. Konstanz: UVK-Verlagsgesellschaft, pp. 303-320.

Schweiger W (2007) Theorien der Mediennutzung: Eine Einführung [Theories of Media Use: An Introduction]. Wiesbaden: VS Verlag für Sozialwissenschaften.

Webster JG (2009) The role of structure in media choice. In: Hartmann T (ed.) Media Choice: A Theoretical and Empirical Overview. New York, Florence, Oxford: Taylor \& Francis, pp. 221-233.

Webster JG (2011) The duality of media: A structurational theory of public attention. Communication Theory 60(3): 43-66.

Webster JG and Wakshlag JJ (1983) A theory of television program choice. Communication Research 10(4): 430-446.

Webster JG, Phalen PF and Lichty LW (2005) Ratings Analysis: The Theory and Practice of Audience Research. Taylor \& Francis. New York, Florence, Oxford,

Zubayr C (1999) The loyal viewer? Patterns of repeat viewing in Germany. Journal of Broadcasting \& Electronic Media 43(3): 346-363.

Zubayr C and Gerhard H (2011) Tendenzen im Zuschauerverhalten: Fernsehgewohnheiten und Fernsehreichweiten im Jahr 2010 [Tendencies of audience behaviour: TV habits and TV reach in 2010]. Media Perspektiven 3: 126-138.

\section{Author biographies}

Markus Lehmkuhl is Senior Researcher at the Freie Universität Berlin. His main research interests concern science journalism and risk communication.

Pepka Boyadjieva is Professor at the Institute for the Study of Societies and Knowledge at the Bulgarian Academy of Sciences.

Yvonne Cunningham is an Adjunct Lecturer at Dublin City University and a founding member of the Celsius Research Group.

Christina Karamanidou is a Postdoctoral Research Fellow at the University of Peloponnese, Greece.

Tuomo Mörä is a Senior Lecturer in Media and Communication Studies at University of Helsinki. 